\title{
Worsening Cardiac Function in a Patient with Friedreich's Ataxia Secondary to Profound Hypothyroidism
}

(®) $\odot \ominus$

Authors

Bradly J. Thrasher, Jennifer Whitham, Jennifer Law

\author{
Affiliation \\ Department of Pediatrics, University of North Carolina, \\ Chapel Hill, NC, USA \\ Key words \\ Freidreich's ataxia, pericardial effusion, hypothyroidism, \\ levothyroxine \\ received $\quad 21.12 .2016$ \\ first decision 01.03 .2017 \\ accepted $\quad 10.03 .2017$ \\ Bibliography \\ DOI https://doi.org/10.1055/s-0043-109432 \\ Exp Clin Endocrinol Diabetes Rep 2018; 5: e6-e8 \\ (C) J. A. Barth Verlag in Georg Thieme Verlag KG Stuttgart . \\ New York \\ ISSN 2196-7407
}

\author{
Correspondence \\ Bradly J. Thrasher, DO \\ Department of Pediatrics \\ University of North Carolina \\ CB\# 7039, Medical School Wing E \\ Chapel Hill, NC 27599 \\ Phone: 919962 2796, Fax: 9199662423 \\ Bradly.Thrasher@unchealth.unc.edu
}

\begin{abstract}
We present a case of declining cardiac function in a patient with Friedreich's Ataxia, however, her worsening cardiac function was not related to her chronic disease. Her declining cardiac function was associated with hypothyroidism that was initially overlooked. The purpose of this article is to remind physicians of the role that thyroid hormone has in cardiac function and overall health. Autoimmune hypothyroidism is a common condition, and physicians should consider screening thyroid function in any patient with poor or worsening cardiac function.
\end{abstract}

\section{Case Report}

A 15 year-old white female with a past medical history significant for Friedreich's ataxia, hypertrophic cardiomyopathy, atrial flutter/ fibrillation, anxiety and depression was found to have a new pericardial effusion on routine echocardiogram.

She also complained of decreased energy levels, swelling of extremities and face and dry skin. Her parents reported that she had gained 25 pounds over 3 months. Vitals were stable and physical exam revealed the following abnormalities: a grade II/VI systolic ejection murmur at the right upper sternal border and apex that radiated to the carotids, slurred speech, an unsteady gate and Tanner stage I breasts.

Aripiprazole had been recently added to her medical management but otherwise no changes to her medications had occurred. Her medications consisted of aspirin, atenolol, baclofen, clonazepam, sertraline, trazodone, losartan, atomoxetine, co-enzyme Q10 and omega-3 polyunsaturated fatty acid. Adverse reactions such as weight gain and edema have been reported as side effects of aripiprazole, atenolol and trazodone, but not pericardial effusions.

Her last echocardiogram, 3 months prior, revealed a severely hypertrophied left ventricle (mass $52.62 \mathrm{~g} / \mathrm{m} 2$ ), trivial aortic valve insufficiency with normal left ventricular systolic function. Her echocardiogram at time of evaluation revealed similar results but now showed a small posterior pericardial effusion.

Also concerning was that her electrocardiogram (ECG) which 3 months prior demonstrated normal sinus rhythm with normal axis, now showed sinus rhythm with right axis deviation, inverted $T$ waves in inferolateral leads and $1-1.5 \mathrm{~mm}$ ST elevation in lead V2. Furthermore, her laboratory workup revealed worsening of her troponin I levels and elevated levels pro-brain natriuretic peptide ( Table 1).

Due to laboratory and imaging studies, there was great concern that her pericardial effusion was secondary to myocardial cell death. However, there was also suspicion that she might have thyroid disease to explain her symptoms and physical exam findings. Thyroid function tests were obtained which revealed a TSH level of $990 \mathrm{mIU} / \mathrm{L}(0.358-3.75)$, Free T4 < $0.5 \mathrm{ng} / \mathrm{dL}(0.76-1.46)$, Thyroid peroxidase antibody $316 \mathrm{IU} / \mathrm{mL}(0-5.6)$, Thyroglobulin antibody $8.6 \mathrm{IU} / \mathrm{mL}(<116)$. Thyroid ultrasound revealed normal thyroid gland size with no nodules and increased vascularity consistent with thyroiditis. Due to her delayed puberty a bone age was obtained that demonstrated a bone age of 12 years and 0 months at a chronological age of 15 years and 0 months. 
Table 1 Laboratory and Imaging Studies.

\begin{tabular}{|c|c|c|c|c|}
\hline Studies & Findings At Diagnosis & $\begin{array}{c}\text { Findings } 3 \text { Months Prior to } \\
\text { Diagnosis }\end{array}$ & $\begin{array}{c}\text { Findings } 4 \text { Months After } \\
\text { Diagnosis }\end{array}$ & Normal Range \\
\hline Troponin I & $0.066 \mathrm{ng} / \mathrm{mL}$ & $0.052 \mathrm{ng} / \mathrm{mL}$ & $0.018 \mathrm{ng} / \mathrm{mL}$ & $\begin{array}{l}0.0-0.034 \mathrm{ng} / \\
\mathrm{mL}\end{array}$ \\
\hline $\begin{array}{l}\text { Pro-Brain Natriuretic } \\
\text { Peptide }\end{array}$ & $421 \mathrm{pg} / \mathrm{mL}$ & --------------- & $169 \mathrm{pg} / \mathrm{mL}$ & $0-125 \mathrm{pg} / \mathrm{mL}$ \\
\hline Ferritin & $38 \mathrm{ng} / \mathrm{mL}$ & $32 \mathrm{ng} / \mathrm{mL}$ & ----------- & $10-70 \mathrm{ng} / \mathrm{mL}$ \\
\hline TSH & $990 \mathrm{mIU} / \mathrm{L}$ & ---------------- & $1.44 \mathrm{mIU} / \mathrm{L}$ & $\begin{array}{l}0.35- \\
3.75 \mathrm{mIU} / \mathrm{L}\end{array}$ \\
\hline Free T4 & $<0.5 \mathrm{ng} / \mathrm{dl}$ & -------------- & $1.24 \mathrm{ng} / \mathrm{dl}$ & $0.76-1.46 \mathrm{ng} / \mathrm{dl}$ \\
\hline ECG & $\begin{array}{l}\text { - Normal sinus rhythm } \\
\text { - Right axis deviation } \\
-1-1.5 \text { ST elevation in lead } \\
\text { V2 }\end{array}$ & $\begin{array}{l}\text { - Normal sinus rhythm } \\
\text { - Normal axis }\end{array}$ & -------------- & \\
\hline Echocardiogram & $\begin{array}{l}\text { - Hypertrophied left ventricle (mass } \\
52.62 \mathrm{~g} / \mathrm{m} 2) \\
\text { - Trivial aortic valve insufficiency } \\
\text { - Small posterior pericardial effusion } \\
(1-3 \mathrm{~mm}) \\
\text { - Normal left ventricular systolic } \\
\text { function }\end{array}$ & $\begin{array}{l}\text { - Hypertrophied left ventricle } \\
\text { - Trivial aortic valve insufficiency } \\
\text { - No pericardial effusion } \\
\text { - Normal left ventricular } \\
\text { function }\end{array}$ & $\begin{array}{l}\text { - Hypertrophied left ventri- } \\
\text { cle (mass } 48.57 \mathrm{~g} / \mathrm{m} 2 \text { ) } \\
\text { - No pericardial effusion } \\
\text { - Normal left ventricular } \\
\text { function }\end{array}$ & \\
\hline
\end{tabular}

The patient was started on low dose thyroid hormone replacement with levothyroxine $12.5 \mathrm{mcg}$ daily, and the dose was slowly titrated up with careful monitoring of her cardiac exam. One month after initiating levothyroxine, her pericardial effusion had resolved. By 4 months her troponin I level was within normal range. She had also developed glandular breast tissue palpable on exam. Four months after initiating levothyroxine therapy, she reached a final treatment dose of $88 \mathrm{mcg}$ daily, which normalized her free T4 and TSH level $(1.24 \mathrm{ng} / \mathrm{dL}$ and $1.44 \mathrm{mIU} / \mathrm{L}$ respectively). The patient reported improved energy levels and that edema of her extremities and face had resolved. Physical examination at that time showed her heart rate and rhythm were regular with no rubs, murmurs or gallops. Her neurologic exam was unchanged. Neck was supple with no thyromegaly. Genitourinary exam revealed Tanner stage 2-3 pubic hair and breasts were Tanner stage 3 .

\section{Discussion}

We report a pediatric patient with Friedreich's ataxia and known cardiac disease with new onset pericardial effusion associated with profound hypothyroidism. Friedreich's ataxia is an autosomal recessive neurodegenerative disorder characterized by spinocerebellar and sensory ataxia and often associated with cardiomyopathy. It is caused by a mutation in the FXN gene, located on chromosome $9 q 21.11$, which codes for frataxin. Individuals with Friedreich's ataxia have a reduced amount of frataxin in their cells. Reduced frataxin levels decrease the activity of proteins that contain iron sulfur clusters which leads to impairment of energy production in the mitochondria [1, 2].

Review of the literature at the time of this report revealed no association between Freidreich's Ataxia and autoimmune hypothyroidism. Even though there is no association between these disease processes, the cardiomyopathy could be exacerbated when they coincide. As individuals have energy production impairment caused by the Friedrech's ataxia and reduced cellular energy expenditure caused by the hypothyroidism [3].

Hypothyroidism is a condition that occurs when the thyroid gland makes little or no thyroid hormone. There are many causes of acquired hypothyroidism but it is most often caused by autoimmune thyroiditis $[4,5]$. Autoimmune thyroiditis is characterized by lymphocytic infiltration of the thyroid gland which results in the production of thyroid specific antibodies. The two targets for thyroid antibodies commonly tested are thyroglobulin, the storage protein of thyroid hormones, and thyroid peroxidase, the rate-limiting enzyme in thyroid hormone production [6]. The prevalence of autoimmune thyroid disease peaks in early to mid-puberty and occurs more frequently in females. It is estimated that $18 \%$ of the general population has positive thyroid antibodies [7]. Hypothyroidism should be considered as a potential etiology for the common and well-known symptoms of fatigue, weight gain, dry skin, hair loss, cold intolerance, edema, depression, menstrual irregularities, or constipation ( $\triangleright$ Fig. 1). If left untreated hypothyroidism may lead to long-term morbidity including growth failure, pubertal delay, and impaired cognitive function and development [8].

A less recognized complication of untreated hypothyroidism is decreased cardiac function characterized by decreased cardiac output, decreased cardiac contractility, bradycardia and an increase in peripheral vascular resistance. Decreased thyroid hormone alters the expression of enzymes, calcium-activated ATPase and phospholamban, which regulate the calcium concentrations in cardiomyocytes. The alterations of these enzymes hinder systolic contraction and diastolic relaxation resulting in reduced cardiac contractility. Peripheral vascular resistance is increased in hypothyroidism due to a decreased release of endothelial-derived relaxation factor from the endothelium of smooth muscle cells. The increase in peripheral vascular resistance results in reduced cardiac output. Common clinical cardiac manifestations resulting from hypothyroidism include bradycardia, exertional dyspnea, hyper- 


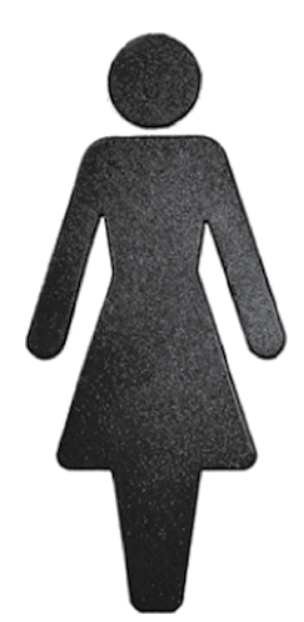

- Weight Gain

- Cold Intolerance

- Constipation

- Hair Loss

- Fatigue

- Dry Skin

- Depression

- Menstrual Irregularities

Fig. 1 Symptoms of hypothryroidism.

tension, edema and pericardial effusions [9]. Pericardial effusions are a common cardiac manifestation of clinical hypothyroidism in adults, however, this is an uncommonly reported complication in children [10]. Another interesting finding in our patient is that she initially had elevated troponin I levels. Increased concentrations of creatine kinase and its MB fraction are commonly seen in hypothyroidic patients, however, the association between hypothyroidism and elevated troponin levels is less clear as conflicting reports can be found $[11,12]$.

Treatment for pericardial effusions secondary to hypothyroidism is best accomplished by administering levothyroxine at a dose sufficient to normalize thyroid function tests. Pericardial effusions typically resolve in 2-12 months after treatment is started [10]. Physicians must be careful to avoid rapid correction of hypothyroidism as it has been shown to cause cardiac injuries and pseudo tumor cerebri $[13,14]$. There are no guidelines as to what dosage to start and how fast to increase, but previous recommendations include using low-dose thyroxine, 25 micrograms or less, and titrating to a final dose over 4.5 to 6 months [15]. Our patient was started on levothyroxine 12.5 micrograms daily and the dose was slowly increased to a final dose of $88 \mathrm{mcg}$ over 4.5 months. She developed no signs or symptoms of pseudotumor cerebri or cardiac failure. She did begin spontaneous puberty after levothyroxine replacement had begun.

\section{Conclusion}

In this reported 15 year old female with Friedrich's ataxia, hypothyroidism manifested in worsening cardiac function, delayed puberty, dry skin, fatigue and weight gain. This case illustrates thyroid hormone's essential role in cardiac function. Autoimmune hypothyroidism commonly occurs, and physicians should consider screening thyroid function in any patient with poor or worsening cardiac function. If profound hypothyroidism is discovered, treatment should be initiated with low dosages of levothyroxine and carefully titrated to a dose sufficient to normalize thyroid function tests.

\section{Conflict of interest}

The authors declare that there are no conflict of interest.

\section{References}

[1] Martelli A, Puccio H. Dysregulation of cellular iron metabolism in Friedreich ataxia: From primary iron-sulfur cluster deficit to mitochondrial iron accumulation. Frontiers in Pharmacology 2014; 5 : doi:10.3389/fphar.2014.00130 PubMed Central PMCID: PMC4042101

[2] Muthuswamy S, Agarwal S. Friedreich ataxia: From the eye of a molecular biologist. Neurologist 2015; 20: 51-55 doi:10.1097| NRL.0000000000000054 PubMed PMID: 26375377

[3] Yehuda-Shnaidman E, Kalderon B, Bar-Tana J. Thyroid hormone, thyromimetics, and metabolic efficiency. Endocr Rev. 2014; 35: 35-58 doi:10.1210/er.2013-1006 PubMed PMID: 23970761

[4] Rallison M, Dobyns BM, Keating FR et al. Occurrence and natural history of chronic lymphocytic thyroiditis in childhood. The Journal of Pediatrics 1975; 85: 675-682

[5] Slatosky ], Shipton B, Wahba H. Thyroiditis: Differential diagnosis and management. American Family Physician. 2000; 61: 1047-1052

[6] Dayan CM, Daniels GH. Chronic autoimmune thyroiditis. New England Journal of Medicine. 1996; 335: 99-107

[7] Hollowell JG, Staehling NW, Flanders WD et al. Serum TSH, T(4), and thyroid antibodies in the united states population (1988 to 1994): National health and nutrition examination survey (NHANES III). J Clin Endocrinol Metab 2002; 87: 489-499

[8] Bettendorf M. Thyroid disorders in children from birth to adolescence. Eur J Nucl Med Mol Imaging. 2002; 29: (Suppl 2): S439-S446

[9] Vargas-Uricoechea $\mathrm{H}$, Sierra-Torres $\mathrm{CH}$. Thyroid hormones and the heart. Horm Mol Biol Clin Investig 2014; 18: 15-26

[10] Sanda S, Newfield RS. A child with pericardial effusion and cardiac tamponade due to previously unrecognized hypothyroidism. J Natl Med Assoc. 2007; 99: 1411-1413

[11] Buschmann IR, Bondke A, Elgeti T et al. Positive cardiac troponin I and $T$ and chest pain in a patient with iatrogenic hypothyroidism and no coronary artery disease. Int J Cardiol. 2007; 115: e83-e85

[12] Ness-Abramof R, Nabriski DA, Shapiro MS et al. Cardiac troponin T is not increased in patients with hypothyroidism. Intern Med J. 2009; 39: 117-120

[13] Hajje G, Saliba Y, Itani T et al. Hypothyroidism and its rapid correction alter cardiac remodeling. PLoS One 2014; 9: e109753 doi:10.1371/ journal.pone.0109753 PubMed PMID: 25333636

[14] Strickler C, Pilon AF. Presumed levothyroxine-induced pseudotumor cerebri in a pediatric patient being treated for congenital hypothyroidism. Clin Ophthalmol 2007; 1: 545-549

[15] Slyper AH, Swenerton P. Experience with low-dose replacement therapy in the initial management of severe pediatric acquired primary hypothyroidism. J Pediatr Endocrinol Metab. 1998; 11: 543-547 